Letter

\title{
Study on Seasonal Variations of Plasma Bubble Occurrence over Hong Kong Area Using GNSS Observations
}

\author{
Long Tang ${ }^{1,2}$, Wu Chen ${ }^{2, *}$, Osei-Poku Louis ${ }^{2}$ and Mingli Chen ${ }^{3}$ \\ 1 School of Civil and Transportation Engineering, Guangdong University of Technology, Guangzhou 510006, \\ China; ltang@gdut.edu.cn \\ 2 Department of Land Surveying and Geo-Informatics, Hong Kong Polytechnic University, Kowloon, \\ Hong Kong; louis.oseipoku@connect.polyu.hk \\ 3 Department of Building Services Engineering, Hong Kong Polytechnic University, Kowloon, Hong Kong; \\ mingli.chen@polyu.edu.hk \\ * Correspondence: wu.chen@polyu.edu.hk
}

Received: 6 July 2020; Accepted: 26 July 2020; Published: 28 July 2020

\begin{abstract}
In this study, the characteristics and causes of the seasonal variations in plasma bubble occurrence over the Hong Kong area were investigated using the local Global Navigation Satellite System (GNSS) network. Generally, the occurrences of plasma bubbles were larger in the two equinoxes than in the two solstices. Furthermore, two seasonal asymmetries in plasma bubble occurrence were observed: plasma bubble activity was more frequent in the spring equinox than in the autumn equinox (equinoctial asymmetry), and more frequent in the summer solstice than in the winter solstice (solstitial asymmetry). The equinoctial asymmetry could be explained using the Rayleigh-Taylor ( $\mathrm{R}-\mathrm{T}$ ) instability mechanism, due to larger $\mathrm{R}-\mathrm{T}$ growth rates in the spring equinox than in the autumn equinox. However, the $\mathrm{R}-\mathrm{T}$ growth rate was smaller in the summer solstice than in the winter solstice, suggesting the R-T instability mechanism was inapplicable to the solstitial asymmetry. Our results showed there were more zonally propagating atmospheric gravity waves (GWs) induced by thunderstorm events over the Hong Kong area in the summer solstice than the winter solstice. So, the solstitial asymmetry could be attributed to the seeding mechanism of thunderstorm-driven atmospheric GWs.
\end{abstract}

Keywords: GNSS; ionosphere; plasma bubble occurrence; seasonal variation

\section{Introduction}

A plasma bubble is one kind of frequent ionospheric weather event in low-latitude areas. The presence of a plasma bubble can cause severe effects on radio signals of communication and navigation systems, such as the Global Navigation Satellite System (GNSS), when they travel through the ionosphere (e.g., [1,2]). As a result, the study of climatology and the predictability of plasma bubbles has attracted extensive focus from scientific communities in recent decades (e.g., [3-8]). Research shows that plasma bubble occurrence presents seasonal variations and longitudinal variations (e.g., $[7,8]$ ). Generally, plasma bubble activity is frequent during equinox periods in the Asian area and African area, during the summer solstice in the Pacific area, and during the northern winter solstice in the American-Atlantic area. In addition, asymmetric seasonal variations in plasma bubble occurrence in different areas have also been reported (e.g., [8]).

Two types of physical mechanisms have been employed to account for the seasonal variations and longitudinal variations in plasma bubble occurrence. The first one is the Rayleigh-Taylor $(\mathrm{R}-\mathrm{T})$ instability mechanism, which is widely applied to explain the formation of plasma bubbles [9]. 
The growth condition of R-T instability is considered to be the important factor that controls the climatology of plasma bubble occurrence. Tsunoda [3] indicated that plasma bubble occurrence was maximized when the geomagnetic field was parallel to the solar terminator. Kil et al. [10] and Sripathi et al. [11] suggested the plasma density might exert an important effect on the seasonal variations in plasma bubble occurrence. Maruyama et al. [12] indicated that meridional wind played a dominant role in the formation of equinoctial asymmetry. The second mechanism is the atmospheric gravity wave (GW) seeding mechanism, which emphasizes the importance of GWs to the generation of plasma bubbles [13,14]. Tsunoda [15] found plasma bubble occurrence was enhanced when a region with frequent GW events was situated near the magnetic equator. Takahashi et al. [16] indicated that medium-scale traveling ionospheric disturbances (MSTIDs) were likely to be a seed source for plasma bubbles.

Due to the longitudinal dependence, it was necessary to study the seasonal variations in plasma bubble occurrence in different areas to fully understand its source mechanism. Here, we focused on the Hong Kong area, which is situated near the magnetic equator. Ji et al. [17] and Kumar et al. [18] studied the seasonal variations in plasma bubble occurrence over this area using GNSS total electron content (TEC) data during 2001-2012 and obtained very meaningful results. However, the cause for the seasonal variations in plasma bubble occurrence was rarely involved in their studies. This study sought to address this gap by looking at the potential sources of the seasonal variations in plasma bubble occurrence.

\section{Data and Methods}

\subsection{Data}

The primary data employed in this study were ionospheric TEC, which was extracted from GNSS observation files. The $30 \mathrm{~s}$ sampling GNSS observation files were acquired from the website of the Hong Kong satellite reference network [19]. GNSS data during 2001-2012 were already processed by Ji et al. [17] and Kumar et al. [18], so their results were directly referenced in this study. Here, GNSS data during a four year period, from 2014 to 2017, were also processed to compare with thunderstorm data (no data during 2001-2012). According to the F10.7 index, solar activity decreased year by year during this period [20]. Figure 1 shows the GNSS station distribution in Hong Kong. Here, only three stations, $\mathrm{HKNP}, \mathrm{HKKT}$, and $\mathrm{HKOH}$, were adopted due to the short distance between adjoining stations. In addition, the global ionospheric map (GIM) data and thunderstorm data during this period were also applied in the analysis. The GIM files were downloaded from the Center for Orbit Determination in Europe (CODE) [21]; the data for thunderstorm activity were obtained by a very low frequency (VLF) detection network we established in this area.

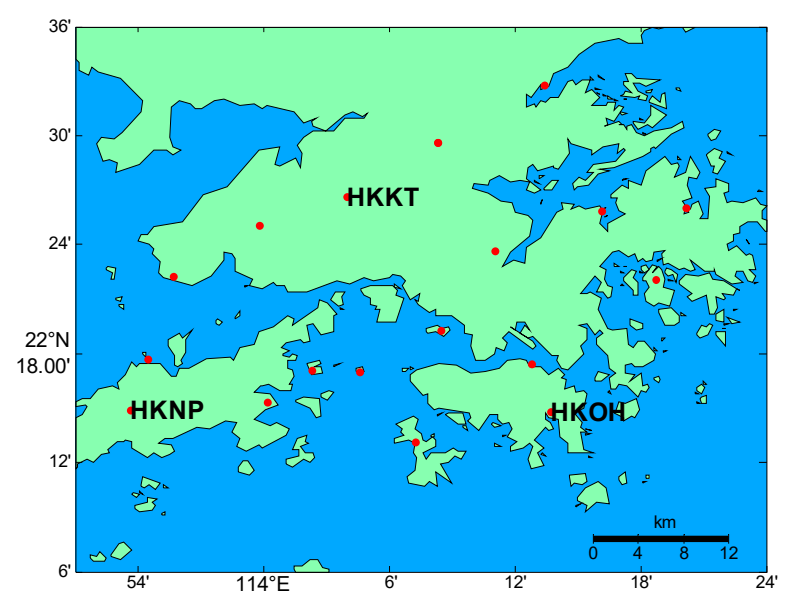

Figure 1. The Global Navigation Satellite System (GNSS) network in Hong Kong. The red points indicate the positions of stations. Three annotated stations, HKNP, HKKT, and HKOH, were applied in this study. 


\subsection{Methods}

To detect plasma bubbles, ionospheric TEC was firstly obtained from GNSS observation files. Ionospheric TEC time series can be computed using the GNSS dual-frequency geometry-free combined carrier phase observations for each pair of satellite and receiver [22]

$$
T E C=k \cdot\left[\left(L_{1}-L_{2}\right)+\left(N_{1}-N_{2}\right)\right]
$$

where $k=f_{1}^{2} f_{2}^{2} /\left[40.3\left(f_{1}^{2}-f_{2}^{2}\right)\right], f_{1}$ and $f_{2}$ are frequencies, $L_{1}$ and $L_{2}$ are carrier phase observations, and $N_{1}$ and $N_{2}$ are carrier phase ambiguities. The carrier phase ambiguities were unknown but were constant. The unit of TEC is TECU $\left(1\right.$ TECU $\left.=10^{16} / \mathrm{m}^{2}\right)$. The elevation mask angle was set as $20^{\circ}$ for each pair of satellite and receiver.

Next, we fit the primitive TEC time series to eliminate the trend term and constant carrier phase ambiguities. Here, the third-order Savitzky-Golay smoothing filter with moving window length of $2 \mathrm{~h}$ was employed $[23,24]$. Then, the detrended TEC (dTEC) time series that might contain plasma bubble were computed as follows

$$
d T E C=T E C-T E C_{f}
$$

where $T E C_{f}$ is the fitted TEC using the Savitzky-Golay smoothing filter. To detect a plasma bubble, a threshold of TEC depletion (minimum) was set to -3 TECU; the adjacent maximum should be smaller than half of the absolute value of TEC depletion. In addition, only the ones that were simultaneously observed by the three employed GNSS stations, namely HKNP, HKKT, and HKOH, were counted as effective plasma bubbles. Figure 2 presents an example of a plasma bubble detected by station HKKT and satellite PRN 23 on January 25, 2014. In this case, the magnitude of TEC depletion was -10.3 TECU, and the two adjacent maximums were 4.2 and 4.5 TECU, respectively.

(a) Primitive TEC and fitted TEC

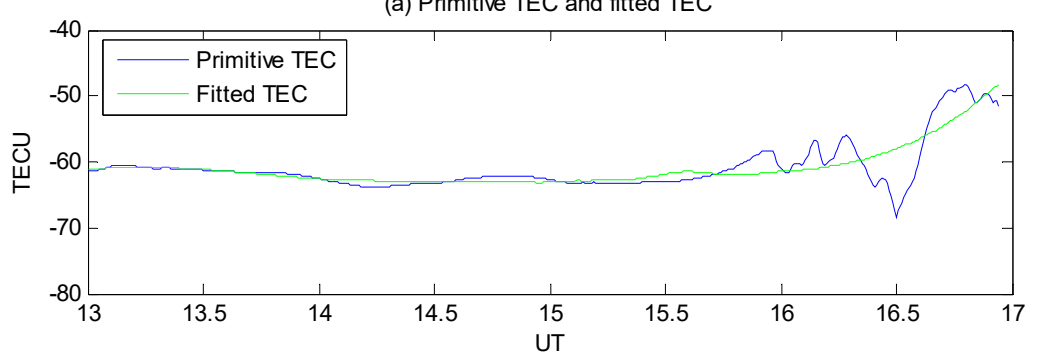

(b) Detrended TEC

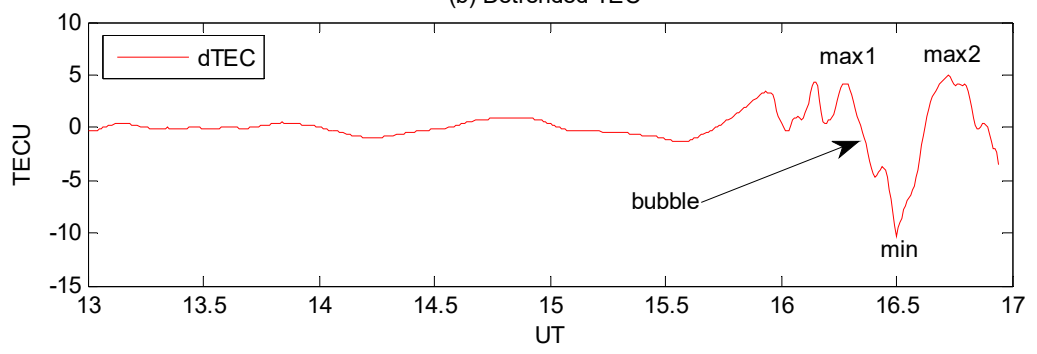

Figure 2. An example of a plasma bubble detected by station HKKT and satellite PRN 23 on January 25, 2014. (a) Primitive total electron content (TEC) time series (blue line) and fitted TEC time series using Savitzky-Golay smoothing filter (green line); (b) detrended TEC time series obtained by subtracting between the primitive and fitted TEC time series (red line). The annotation "min" represents TEC depletion (minimum) and the annotations "max1" and "max2" represent the adjacent two maximums.

After detecting a plasma bubble, we could calculate the seasonal occurrence. A year was divided into four seasons: the spring equinox (from February to April), the summer solstice (from May to July), the autumn equinox (from August to October), and the winter solstice (from November to January). The monthly plasma bubble occurrence was computed by dividing the number of days with plasma 
bubbles in a month by the total number of days in the month. Then, the seasonal plasma bubble occurrence was obtained by averaging the monthly plasma bubble occurrence of the three months comprising a season.

\section{Results}

Figure 3 presents the observed seasonal plasma bubble occurrence during each year from 2014 to 2017. Figure 4 presents average solar F10.7 indices for different seasons during each year from 2014 to 2017. Obviously, plasma bubble occurrence was maximum during the high solar activity year of 2014 and minimum during the low solar activity year of 2017, indicating that it was dependent on solar activity. As seen in Figure 3, the occurrences of plasma bubbles were significantly larger in the two equinoxes than in the two solstices in the high solar activity years of 2014 and 2015. In the low solar activity year of 2017, the difference in plasma bubble occurrence between the summer solstice and the two equinoxes was not obvious.

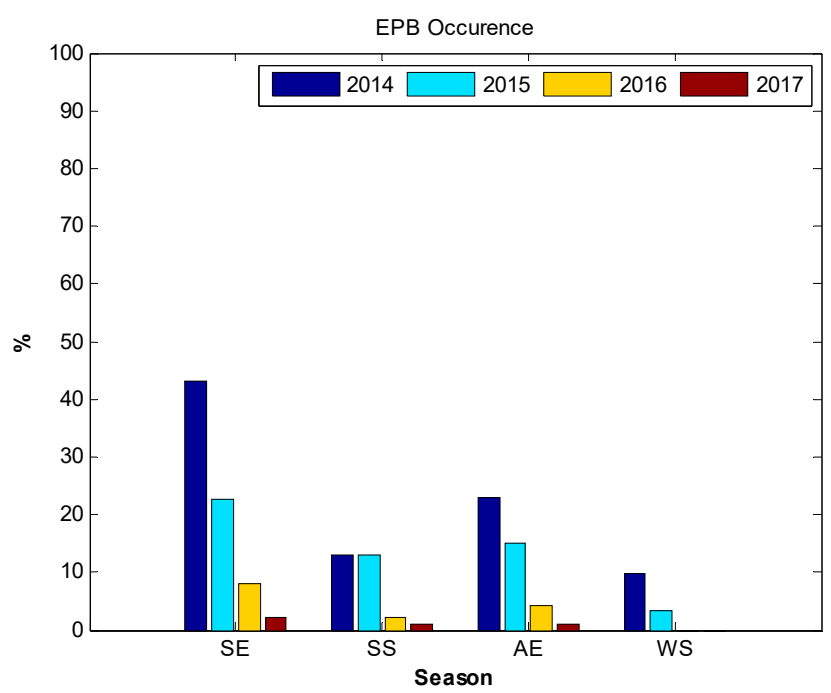

Figure 3. The seasonal plasma bubble occurrence during each year from 2014 to 2017. SE, SS, AE, and WS represent the spring equinox, summer solstice, autumn equinox, and winter solstice, respectively.

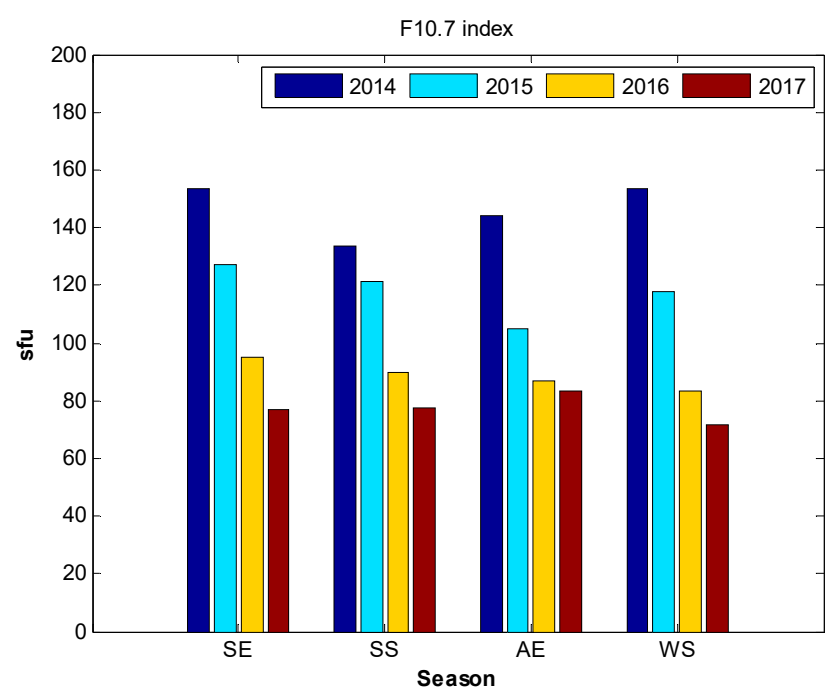

Figure 4. The average solar F10.7 index for different seasons during each year from 2014 to 2017. $\mathrm{SE}, \mathrm{SS}, \mathrm{AE}$, and WS represent the spring equinox, summer solstice, autumn equinox, and winter solstice, respectively. 
It can be seen from Figure 3 that the plasma bubble occurrence was greater in the spring equinox than in the autumn equinox, especially during the high solar activity years of 2014 and 2015, indicating that the seasonal variations in plasma bubble occurrence presented equinoctial asymmetry. As for the solstices, the plasma bubble activity was more frequent in the summer solstice than in the winter solstice. In the winter solstice, there were no plasma bubbles during the low solar activity years of 2016 and 2017 (Figure 3). This indicated that solstitial asymmetry also existed in seasonal variations in plasma bubble occurrence.

The seasonal variation characteristics of plasma bubble occurrence during 2001-2012 over the Hong Kong area were investigated by Ji et al. [17] and Kumar et al. [18]. According to their studies, larger values of plasma bubble occurrence were observed during high solar activity years (maximum in 2002). The plasma bubble activity was generally more frequent in the two equinoxes than in the two solstices, except during 2007 and 2008 (low solar activity). In addition, the equinoctial asymmetry in plasma bubble occurrence, namely, a larger value in the spring equinox, was also observed during 2002-2012. In 2001, a larger value of plasma bubble occurrence was observed in the autumn equinox. As for the solstitial asymmetry, it did not attract their attention and was not involved in their studies. Actually, the solstitial asymmetry in plasma bubble occurrence was also observable during 2001-2012 (Figure 16 in Ji et al. [17] and Figure 3 in Kumar et al. [18]). A larger value was generally observed in the summer solstice; an exception was in 2004, when the larger values were observed in the winter solstice.

The results observed during these 16 years (2001-2012 and 2014-2017) showed that the plasma bubble occurrence over the Hong Kong area presented significant seasonal variations. Generally, the occurrences of plasma bubbles were larger in the two equinoxes than in the two solstices. Furthermore, plasma bubble activity was more frequent in the spring equinox than in the autumn equinox and more frequent in the summer solstice than in the winter solstice.

\section{Discussion}

The R-T instability mechanism is widely applied to explain the formation of plasma bubbles, which can be assessed using the R-T growth rate. The flux tube integrated R-T growth rate can be calculated using following formula [9]

$$
\gamma_{R T}=\frac{\Sigma_{P}^{F}}{\Sigma_{P}^{F}+\Sigma_{P}^{E}}\left(V_{P}-U_{L}^{P}-\frac{g_{e}}{v_{e f f}^{F}}\right) K^{F}-R_{T}
$$

where $\Sigma_{P}^{E}$ and $\Sigma_{P}^{F}$ are integrated Pedersen conductivities in the E region and F region, respectively; $U_{L}^{P}$ is the integrated neutral wind; $V_{P}$ is the integrated upward drift speed; $g_{e}$ and $v_{e f f}^{F}$ are the effective gravity and effective ion-neural collision frequency, respectively; $K^{F}$ is the $\mathrm{F}$ region integrated electron content gradient; and $R^{T}$ is the recombination rate.

$\mathrm{Wu}$ [25] and $\mathrm{Wu}$ [26] calculated the R-T growth rate at 18:00 local time (LT) for the globe using Thermosphere Ionosphere Electrodynamics General Circulation Model (TIEGCM) during the years of 2003 (solar maximum), 2006, and 2009 (solar minimum). The results showed that the growth rate was positively correlated to the solar activity, which was consistent with our observed variations in plasma bubble occurrence. In addition, the $\mathrm{R}-\mathrm{T}$ growth rate presented similar seasonal variations and longitudinal variations during each year, although different in magnitude. Here, we took the R-T growth rate during the year of 2006 as an example, shown in Figure 5.

As seen in Figure 5, the R-T growth rate was high during the two equinoxes and low during the two solstices over the Hong Kong area (about longitude 110-120 $)$. In addition, there were more days that the growth rate was greater than $60^{*} 10^{-5} / \mathrm{s}$ (light green area) during the spring equinox than the autumn equinox. These can explain the characteristics of plasma bubble occurrence, namely that a larger value was observed during the two equinoxes and it showed equinoctial asymmetry. During the two equinoxes, the solar terminator aligned with the geomagnetic field, leading to enhanced plasma bubble activity [3]. 


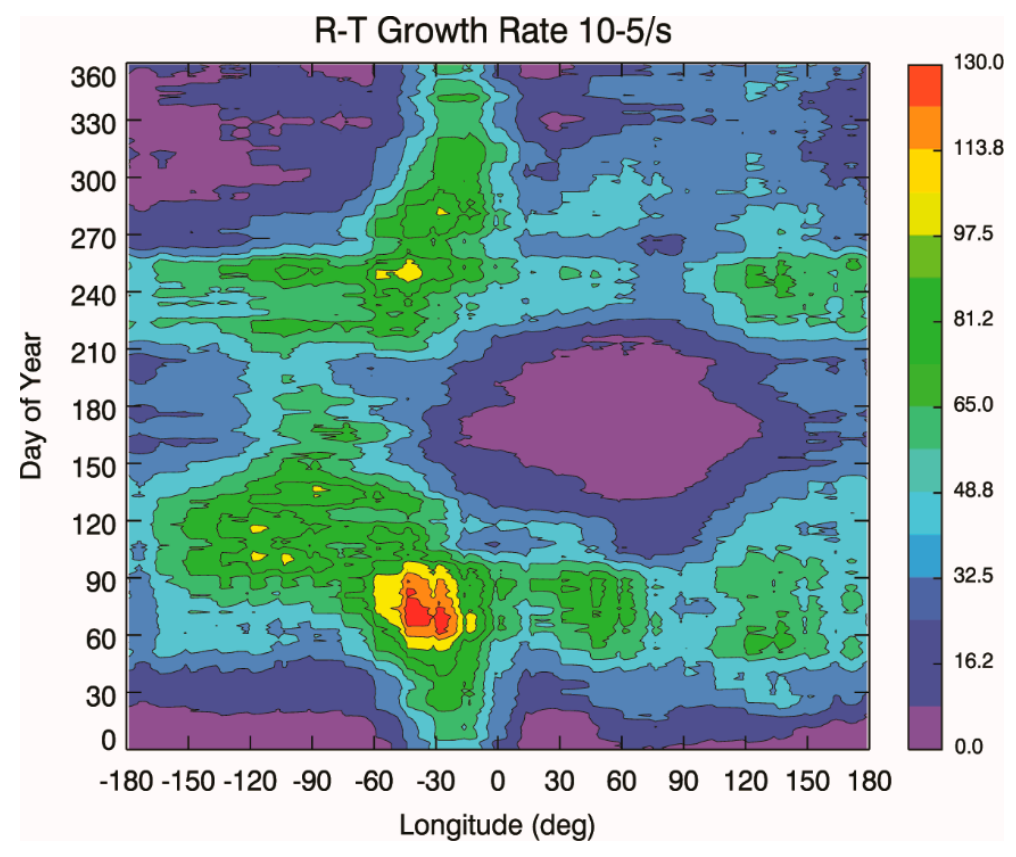

Figure 5. Seasonal and longitudinal variations of the Rayleigh-Taylor instability growth rate at $270 \mathrm{~km}$ during the year of 2006 (Figure 2a in $\mathrm{Wu}$ [25]).

As shown in Figure 4, differences in solar activity during the two equinoxes was not obvious, suggesting that it was not the cause for the equinoctial asymmetry. Kil et al. [10] suggested the plasma density might exert an important effect on the seasonal variations in plasma bubble occurrence. Sripathi et al. [11] indicated that electron density was important to the formation of equinoctial asymmetry. Using GIM, we calculated the average ionospheric TEC (integrated electron density) at 18:00 LT over the Hong Kong area for different seasons during each year from 2014 to 2017, shown in Figure 6. As seen in Figure 6, ionospheric TEC during the spring equinox was significantly larger than during the autumn equinox, especially in high solar activity years. This result suggested the ionospheric TEC (or electron density) was likely an important factor for the equinoctial asymmetry. According to Equation (3), ionospheric TEC is not an explicit parameter to calculate the R-T growth rate. It could affect the $\mathrm{R}-\mathrm{T}$ growth rate by the variation of the polarization electric field. When the F-region TEC was large, short circuiting of the polarization electric field driven in the F-region weakened, so that a larger polarization electric field was generated [9]. Then, the expression $\Sigma_{P}^{F} /\left(\Sigma_{P}^{F}+\Sigma_{P}^{E}\right)$ in Equation (3) became large (getting close to unity), leading to a large R-T growth rate.

We discussed the solstitial asymmetry in plasma bubble occurrence. As can be seen from Figure 5, $\mathrm{R}-\mathrm{T}$ growth rate was almost lower than $10^{*} 10^{-5} / \mathrm{s}$ during the summer solstice, whereas its value was about $20^{*} 10^{-5}-30^{*} 10^{-5} / \mathrm{s}$ during the winter solstice over the Hong Kong area. That is to say, the variations in the $\mathrm{R}-\mathrm{T}$ growth rate during the two solstices were not consistent with that of plasma bubble occurrence. In addition, ionospheric TEC was also not always larger during the summer solstice than during the winter solstice (seen in Figure 6). This suggested that, apart from the R-T growth rate, other factors could also exert effects on the formation of solstitial asymmetry.

Research showed that atmospheric GWs (or MSTIDs) associated with the polarization electric fields also played an important role in plasma bubble formation [13-16]. To generate the polarization electric fields, the phase front (perpendicular to propagation direction) of GWs should be approximately aligned with the geomagnetic direction [27]. Therefore, zonally propagating GWs were necessary due to the meridional magnetic field line. MSTIDs were signals of atmospheric GWs in the ionosphere, which can be called as ionospheric GWs. Here, we investigated the ionospheric GWs as a proxy of atmospheric GWs. 


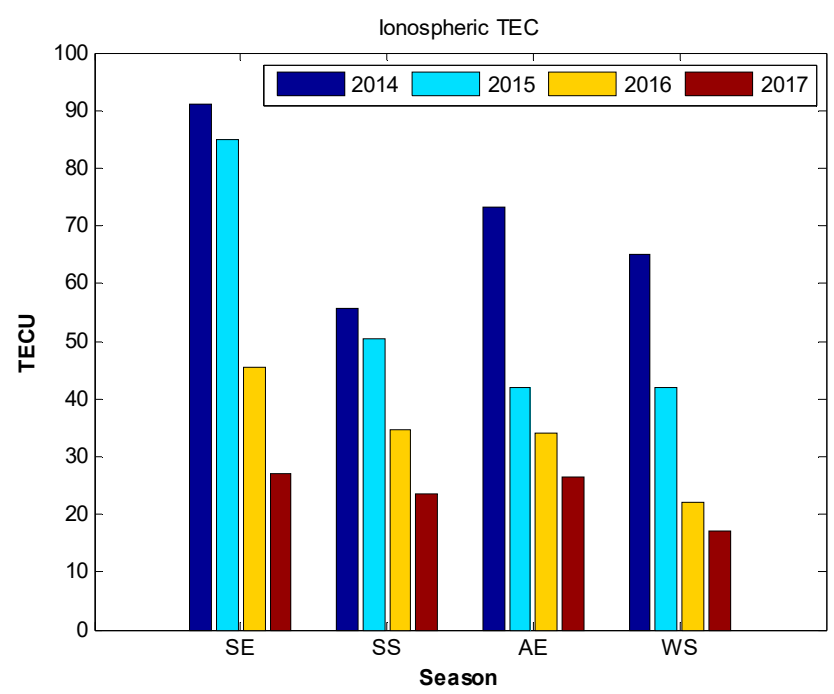

Figure 6. The average ionospheric TEC at 18:00 local time (LT) for different seasons during each year from 2014 to 2017. SE, SS, AE, and WS represent the spring equinox, summer solstice, autumn equinox, and winter solstice, respectively.

Figure 7 presents the ionospheric detrended TEC (dTEC) series extracted by station HKKT during the years of 2014 and 2017 using the method in Tang et al. [24] (other stations had similar results). As shown in Figure 7, the ionospheric dTEC series were detected during all months over the Hong Kong area. There were more days featuring high-amplitude ionospheric dTEC series during the summer solstice than the winter solstice. We employed the dTEC series extracted by the three stations, HKKT, HKNP, and $\mathrm{HKOH}$, to calculate the propagation direction of GWs using the method in Garrison et al. [28]. The propagation directions of ionospheric GWs at 17:30-18:30 LT for the two solstices during the years of 2014 and 2017 are shown in Figure 8. This time interval of ionospheric GWs was chosen due to the fact that plasma bubbles generally occurred after sunset when the enhanced eastward electric field destabilized the ionosphere [17]. As seen in Figure 8, there were more days featuring azimuth of ionospheric GWs around $-90^{\circ}$ or $90^{\circ}$ during the summer solstice than the winter solstice during both the high solar activity year of 2014 and the low solar activity year of 2017. This meant that zonally propagating GWs were in existence during the summer solstice, leading to enhanced plasma bubble activity.
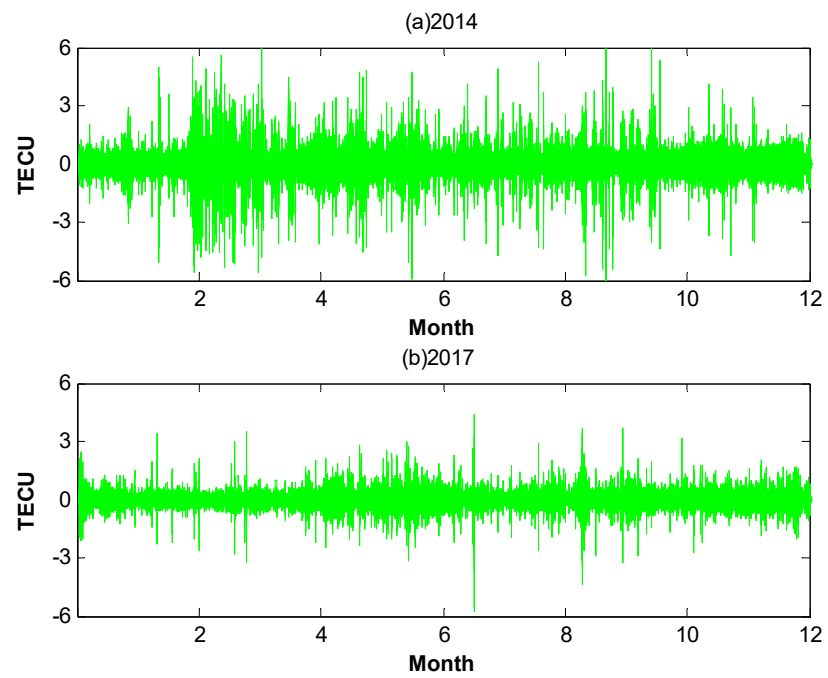

Figure 7. Ionospheric detrended TEC (dTEC) series extracted by GNSS station HKKT during the years of 2014 and 2017. 

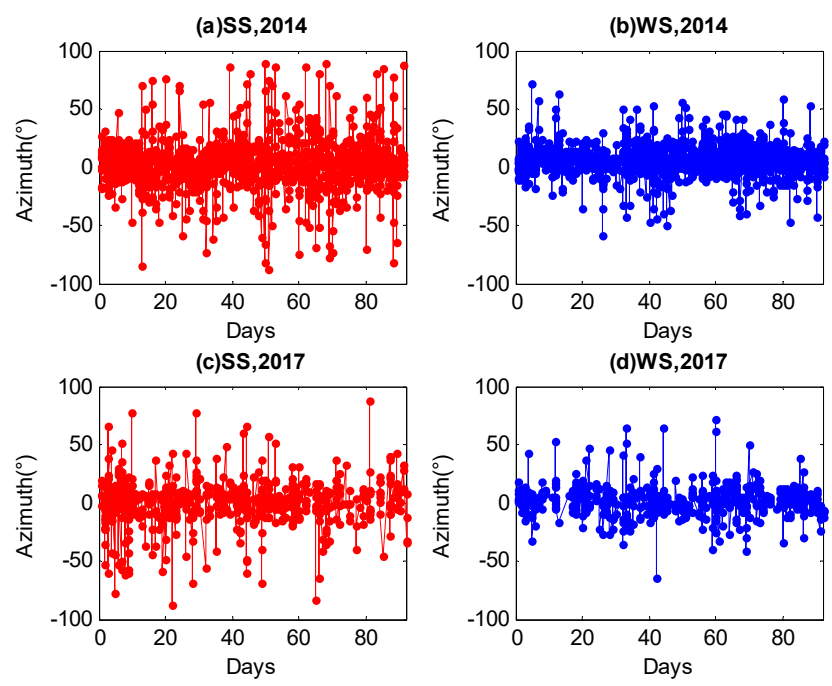

Figure 8. Propagation direction of ionospheric gravity waves (GWs) at 17:30-18:30 LT for the two solstices during the years of 2014 and 2017. SS represents the summer solstice and WS represents the winter solstice. Here, the scope of the azimuth is $-90^{\circ}$ to $90^{\circ}$.

The above analysis suggested the GW seeding mechanism was responsible for the formation of solstitial asymmetry in plasma bubble occurrence over the Hong Kong area. The source of the GWs needs to be further explored. According to the local VLF detection network, the Hong Kong area had frequent thunderstorm activity during March-October. Using the processing method in Tang et al. [29], we obtained the average thunderstorm coverage area (grid counts) for different seasons during each year from 2014 to 2017, shown in Figure 9. As seen in Figure 9, thunderstorm activity during the summer solstice was significantly stronger than during the winter solstice. Tang et al. [29] analyzed the relationship between thunderstorms and the ionospheric GWs over the Hong Kong area during the years of 2014-2017. Their research indicated that thunderstorm events were the main source of GWs, especially during high thunderstorm days, such as the summer solstice.

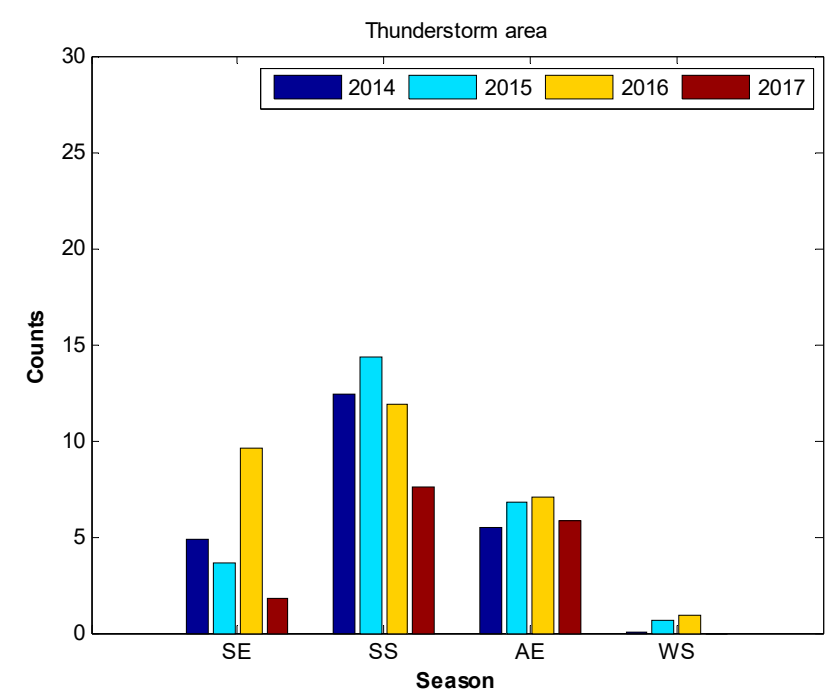

Figure 9. The average thunderstorm area for different seasons during each year from 2014 to 2017. $\mathrm{SE}, \mathrm{SS}, \mathrm{AE}$, and WS represent the spring equinox, summer solstice, autumn equinox, and winter solstice, respectively.

According to the above analysis, a conclusion could be drawn that the solstitial asymmetry in plasma bubble occurrence over the Hong Kong area could be attributed to the seeding mechanism of 
thunderstorm-driven GWs. When the growth rate of R-T instability was small, the GW seeding could play a dominant role in the process of plasma bubble generation. This could explain the reported exceptions during 2007 and 2008, in which plasma bubble occurrence was greater in the summer solstice than in the spring equinox over the Hong Kong area.

\section{Conclusions}

In this study, the seasonal variations in plasma bubble occurrence over the Hong Kong area were investigated using the local GNSS network. Furthermore, the causes of seasonal variation characteristics were also carefully explored. The main results and conclusions are listed as follows:

1. The occurrences of plasma bubble were generally larger in the two equinoxes than in the two solstices. During the two equinoxes, the solar terminator aligned with the geomagnetic field, leading to enhanced plasma bubble activity.

2. Plasma bubble activity was more frequent in the spring equinox than in the autumn equinox (equinoctial asymmetry). The equinoctial asymmetry could be explained by the R-T instability mechanism, due to the larger $\mathrm{R}-\mathrm{T}$ growth rate in the spring equinox than in the autumn equinox. Ionospheric TEC (or electron density) was likely an important factor in the equinoctial asymmetry.

3. The plasma bubble occurrence was greater in the summer solstice than in the winter solstice (solstitial asymmetry). The R-T instability mechanism was not suitable for the formation of solstitial asymmetry, due to the lower $\mathrm{R}-\mathrm{T}$ growth rate in the summer solstice compared to that of the winter solstice. The solstitial asymmetry could be attributed to the seeding mechanism of thunderstorm-driven GWs.

In other words, the seasonal variations in plasma bubble occurrence over the Hong Kong area depended on combined effects of R-T instability and GW seeding. The reported exceptions during 2001 and 2004 need further research in the future work.

Author Contributions: L.T. contributed to data analysis and led manuscript writing. W.C. supervised this study. O.-P.L. contributed to manuscript editing. M.C. contributed to data processing. All authors have read and agreed to the published version of the manuscript.

Funding: This research was funded by the National Natural Science Foundation of China (Grant number 41804021, 41874031) and the Natural Science Foundation of Guangdong Province (Grant number 2017A030310242).

Acknowledgments: The authors thank the SMO in Hong Kong and the CODE for providing GNSS data and GIM data. The authors also thank the anonymous reviewers for valuable and helpful comments.

Conflicts of Interest: The authors declare no conflict of interest.

\section{References}

1. Chen, W.; Gao, S.; Hu, C.; Chen, Y.; Ding, X. Effects of ionospheric disturbances on GPS observation in low latitude area. GPS Solut. 2008, 12, 33-41. [CrossRef]

2. Kelley, M.C.; Makela, J.J.; de La Beaujardière, O.; Retterer, J. Convective ionospheric storms: A review. Rev. Geophys. 2011, 49. [CrossRef]

3. Tsunoda, R.T. Control of the seasonal and longitudinal occurrence of equatorial scintillations by the longitudinal gradient in integrated E region Pedersen conductivity. J. Geophys. Res. Atmos. 1985, 90, 447-456. [CrossRef]

4. Aarons, J. The longitudinal morphology of equatorial F-layer irregularities relevant to their occurrence. Space Sci. Rev. 1993, 63, 209-243. [CrossRef]

5. Sobral, J.; Abdu, M.A.; Takahashi, H.; Taylor, M.J.; De Paula, E.R.; Zamlutti, C.J.; De Aquino, M.G.; Borba, G.L. Ionospheric plasma bubble climatology over Brazil based on 22 years (1977-1998) of $630 \mathrm{~nm}$ airglow observations. J. Atmos. Sol.-Terr. Phys. 2002, 64, 1517-1524. [CrossRef]

6. Burke, W.J.; Su, S.Y.; Gentile, L.C.; Huang, C.Y.; Valladares, C.E. Longitudinal variability of equatorial plasma bubbles observed by DMSP and ROCSAT-1. J. Geophys. Res. Space Phys. 2004, 109, 12301. [CrossRef] 
7. Makela, J.J.; Ledvina, B.M.; Kelley, M.C.; Kintner, P.M. Analysis of the seasonal variations of equatorial plasma bubble occurrence observed from Haleakala, Hawaii. Ann. Geophys. 2004, 22, 3109-3121. [CrossRef]

8. Nishioka, M.; Saito, A.; Tsugawa, T. Occurrence characteristics of plasma bubble derived from global ground-based GPS receiver networks. J. Geophys. Res. Space Phys. 2008, 113. [CrossRef]

9. Sultan, P.J. Linear theory and modeling of the Rayleigh-Taylor instability leading to the occurrence of equatorial spreadF. J. Geophys. Res. Space Phys. 1996, 101, 26875-26891. [CrossRef]

10. Kil, H.; Demajistre, R.; Paxton, L.J. F-region plasma distribution seen from TIMED/GUVI and its relation to the equatorial spread F activity. Geophys. Res. Lett. 2004, 31, 179-211. [CrossRef]

11. Sripathi, S.; Kakad, B.; Bhattacharyya, A. Study of equinoctial asymmetry in the Equatorial Spread F (ESF) irregularities over Indian region using multi-instrument observations in the descending phase of solar cycle 23. J. Geophys. Res. Space Phys. 2011, 116. [CrossRef]

12. Maruyama, T.; Saito, S.; Kawamura, M.; Nozaki, K.; Krall, J.; Huba, J.D. Equinoctial asymmetry of a low-latitude ionosphere-thermosphere system and equatorial irregularities: Evidence for meridional wind control. Ann. Geophys. 2009, 27, 2027-2034. [CrossRef]

13. Röttger, J. Equatorial spread-F by electric fields and atmospheric gravity waves generated by thunderstorms. J. Atmospheric Terr. Phys. 1981, 43, 453-462. [CrossRef]

14. McClure, J.P.; Singh, S.; Bamgboye, D.K.; Johnson, F.S.; Kil, H. Occurrence of equatorial F region irregularities: Evidence for topside seeding. J. Geophys. Res. 1998, 103, 29119-29135. [CrossRef]

15. Tsunoda, R.T. On equatorial spreadF: Establishing a seeding hypothesis. J. Geophys. Res. Space Phys. 2010, 115. [CrossRef]

16. Takahashi, H.; Wrasse, C.M.; Figueiredo, C.A.O.B.; Barros, D.; Abdu, M.A.; Otsuka, Y.; Shiokawa, K. Equatorial plasma bubble seeding by MSTIDs in the ionosphere. Prog. Earth Planet. Sci. 2018, 5, 32. [CrossRef]

17. Ji, S.; Chen, W.; Wang, Z.; Xu, Y.; Weng, D.; Wan, J.; Fan, Y.; Huang, B.; Fan, S.; Sun, G. A study of occurrence characteristics of plasma bubbles over Hong Kong area. Adv. Space Res. 2013, 52, 194-1958. [CrossRef]

18. Kumar, S.; Chen, W.; Liu, Z.; Ji, S. Effects of solar and geomagnetic activity on the occurrence of equatorial plasma bubbles over Hong Kong. J. Geophys. Res. Space Phys. 2016, 121, 9164-9178. [CrossRef]

19. Hong Kong Satellite Reference Network. Available online: Ftp://ftp.geodetic.gov.hk (accessed on 28 July 2020).

20. Space Weather Center of Japan. Available online: http://swc.nict.go.jp (accessed on 28 July 2020).

21. Center for Orbit Determination in Europe. Available online: http://ftp.aiub.unibe.ch/CODE (accessed on 28 July 2020).

22. Tang, L.; Li, Z.; Zhou, B. Large-area tsunami signatures in ionosphere observed by GPS TEC after the 2011 Tohoku earthquake. GPS Solut. 2018, 22, 93. [CrossRef]

23. Portillo, A.; Herraiz, M.; Radicella, S.M.; Ciraolo, L. Equatorial plasma bubbles studied using African slant total electron content observations. J. Atmos. Sol. Terr. Phys. 2008, 70, 907-917. [CrossRef]

24. Savitzky, A.; Golay, M.J.E. Smoothing and Differentiation of Data by Simplified Least Squares Procedures. Anal. Chem. 1964, 36, 1627-1639. [CrossRef]

25. Wu, Q. Longitudinal and seasonal variation of the equatorial flux tube integrated Rayleigh-Taylor instability growth rate. J. Geophys. Res. Space Phys. 2015, 120. [CrossRef]

26. Wu, Q. Solar effect on the Rayleigh-Taylor instability growth rate as simulated by the NCAR TIEGCM. J. Atmos. Sol.-Terr. Phys. 2017, 156, 97-102. [CrossRef]

27. Huang, C.-S.; Kelley, M.C. Nonlinear evolution of equatorial spread F: 1 . On the role of plasma instabilities and spatial resonance associated with gravity wave seeding. J. Geophys. Res. Space Phys. 1996, 101, $283-292$. [CrossRef]

28. Garrison, J.L.; Lee, S.-C.G.; Haase, J.S.; Calais, E. A method for detecting ionospheric disturbances and estimating their propagation speed and direction using a large GPS network. Radio Sci. 2007, 42. [CrossRef]

29. Tang, L.; Chen, W.; Chen, M.; Louis, O.P. Statistical Observation of Thunderstorm-Induced Ionospheric Gravity Waves above Low-Latitude Areas in the Northern Hemisphere. Remote Sens. 2019, 11, 2732. [CrossRef]

(C) 2020 by the authors. Licensee MDPI, Basel, Switzerland. This article is an open access article distributed under the terms and conditions of the Creative Commons Attribution (CC BY) license (http://creativecommons.org/licenses/by/4.0/). 